\title{
Adult neurogenesis in Provence: Where history meets science
}

\author{
Mirjana Maletic-Savatic $(\bowtie)^{1}$, Michael Valenzuela ${ }^{2}$ \\ ${ }^{I}$ Departments of Pediatrics and Neuroscience, Baylor College of Medicine; Jan and Dan Duncan Neurological Research Institute at Texas \\ Children's Hospital, Texas 77030, USA \\ ${ }^{2}$ Regenerative Neuroscience Group, Brain and Mind Centre, University of Sydney, NSW 2006, Australia
}

(C) Higher Education Press and Springer-Verlag Berlin Heidelberg 2016

In the idyllic medieval village of Sernhac situated in the heart of old Provence, in September 2015 Workshop organizers Michael Valenzuela and Mirjana Maletic-Savatic brought together scientists around the globe to participate in the third biannual workshop, this time on adult neurogenesis. The workshop covered diverse aspects of neurogenesis, both in animal and human, presented in this Special Issue of Frontiers in Biology as a selection of articles that highlight new discoveries and challenges along the way.

Since its discovery in 1962 and establishment in the 1990s, adult neurogenesis has captured the mind of scientists, clinicians, and the public alike. Adult neurogenesis promises new avenues for brain regeneration and the treatment of a wide variety of neurological and mental disorders. Underlying this is a rapidly expanding understanding of neural stem cells and precursors that are the biological basis for neurogenesis. These cells have been envisioned as the source of donor cells for transplantation, as vectors for gene therapy and as endogenous targets for pharmacological upregulation.

However, if we are to truly exploit neurogenesis to halt or reverse brain disorders, we need to understand better the core molecular machinery that governs the fate and function of neural stem cells and their progeny. The current status of such knowledge garnered on animal studies is succinctly summarized in Semerci and Maletic-Savatic (2016).

Functional relevance of adult neurogenesis is arguably the most challenging question, especially in humans. Hvoslef-Eide and Oomen (2016) critically review evidence for newborn neurons playing a role in learning and memory, including pattern separation, temporal separation of memory events, forgetting, and cognitive flexibility, as well as mood control. Critical to this process is the neurogenic environment, conceptually everything outside of the subgranular zone. For the longest time, we have understood the devastating impact of chronic stress on neurogenesis, a topic comprehensively analyzed by Lucassen and Oomen (2016). This work underscored neurogenic theories of depression and therapeutic mechanisms. Antidepressants typically increase hippocampal neurogenesis in animal models, but their use in patients can lead to increased risk of suicide particularly during adolescence (Bottelier et al., 2016).

Henriette van Praag (National Institute for Aging, USA) underlined the positive impact that behavioral changes can have on neurogenesis, in particular aerobic exercise. Positive, low-risk and broadly implementable neurogenic interventions are of great interest and this work is rapidly expanding into nutraceuticals. These new frontiers were elegantly presented by Scott Small (Columbia University), who presented his work showing that natural products such as dietary flavanols, resveratrol, and green tea compounds, influence dentate gyrus metabolism and neurogenesis.

Gene-metabolome interactions are likely to be relevant for the division and differentiation of neuroprogenitors, and hence are of great interest for understanding development of mental health disorders (Petrovchich et al., 2016). Furthermore, given the circuitry of the dentate gyrus, including local and long-range synapses, regulation of adult 
neurogenesis is likely to include vascular and cerebrospinal fluid-derived signals (Arnaud et al., 2016; Ermine et al., 2016).

At the Workshop, two studies introduced new horizons of the field. Konig et al. (2016) review the literature on the existence of independent neuroprecursor/neuroblast populations that may represent silent sources for cortical plasticity, an intriguing aspect that awaits more research. Finally, as we move toward the translation of the discoveries to human disorders, Troung et al. (2016) critically review the promise and pitfalls of modeling neurodegenerative diseases using different sources of stem cells.

Sernhac, with its rich history and exquisite nature, provided the perfect setting for the Workshop. In Roman times, Sernhac was the heart of the region, supplying water to neighboring towns from the Pont du Gard aqueduct, a technical masterpiece still standing today as a work of art. Similarly, the Workshop stimulated exchange of knowledge and provided a fountain of new ideas to fuel new discoveries in the field of adult neurogenesis.

\section{References}

Arnaud K, Di Nardo A A (2016). Choroid plexus trophic factors in the developing and adult brain. Front Biol, 11(3): 214-221

Bottelier M A, Schrantee A, van Wingen G, Ruhe H G, de Ruiter M B, Reneman L (2016). A power analysis for future clinical trials on the potential adverse effects of SSRIs on amygdala reactivity. Front Biol, 11(3): 256-259

Ermine C M, Wright J L, Parish C L, Stanić D, Thompson L H (2016). Combined immunohistochemical and retrograde tracing reveals little evidence for innervation of the rat dentate gyrus from midbrain dopamine neurons. Front Biol, 11(3): 246-255

Hvoslef-Eide M, Oomen C (2016). Adult neurogenesis and pattern separation: A critical evaluation of data, tasks and interpretation. Front Biol, 11 (3): $168-181$

König R, Benedetti B, Rotheneichner P, Q'Sullivan, Kreutzer C, Belles M, Nacher J, Weiger M T, Aigner L, Couillard-Després S (2016). Distribution and fate of DCX/PSA-NCAM expressing cells in the adult mammalian cortex: A local reservoir for adult cortical neuroplasticity? Front Biol, 11(3): 193-213

Lucassen P, Oomen C A (2016). Stress, hippocampal neurogenesis and cognition: functional correlations. Front Biol, 11(3): 182-192

Petrovchich I, Sosinsky A, Konde A, Archibald A, Henderson D, Maletic-Savatic M, Milanovic S (2016). Metabolomics in Schizophrenia and Major Depressive Disorder. Front Biol, 11(3): 222-231

Semerci F, Maletic-Savatic M (2016). Transgenic mouse models for studying adult neurogenesis. Front Biol, 11(3): 151-167

Truong A, Si E, Duncan T, Valenzuela M (2016). Modelling neurodegenerative disorders in adult somatic cells: A critical review. Front Biol, 11(3): $232-245$ 